\title{
A Time Modulated Printed Dipole Antenna Array for Beam Steering Application
}

\author{
Ruchi Gahley ${ }^{1}$ and Banani Basu ${ }^{2}$ \\ ${ }^{1}$ Department of Electronics and Communication Engineering, Thapar University, Patiala 147004, India \\ ${ }^{2}$ Department of Electronics and Telecommunication Engineering, National Institute of Technology, Silchar 788010, India \\ Correspondence should be addressed to Banani Basu; basu_banani@yahoo.in
}

Received 5 October 2016; Revised 18 December 2016; Accepted 4 January 2017; Published 16 February 2017

Academic Editor: Sotirios K. Goudos

Copyright (c) 2017 Ruchi Gahley and Banani Basu. This is an open access article distributed under the Creative Commons Attribution License, which permits unrestricted use, distribution, and reproduction in any medium, provided the original work is properly cited.

\begin{abstract}
This paper presents time modulated beam steered antenna array without phase shifters. The beam steering is analyzed considering a two-element time modulated antenna array (TMAA) of printed dipoles with microstrip via-hole balun. The proposed array resonates at the Industrial, Scientific, and Medical (ISM) radio bands, $2.45 \mathrm{GHz}$ and $5.8 \mathrm{GHz}$, and offers wide bandwidth inherited due to modified structure of ground plane. Array elements are excited by complex exponential excitation signal through broadband power divider and radio frequency (RF) switches to achieve amplitude and phase variation without phase shifters. Differential Evolution algorithm is used to modify the time sequences of the RF switches connected to the antennas to generate radiation pattern with optimum dynamic efficiency by suppressing sideband radiations. Also switch-on time instant of RF switch connected to the subsequent element is modulated to steer the beam towards different directions. The proposed prototype is fabricated followed by parametric optimization. The fabrication results agree significantly well with simulated results.
\end{abstract}

\section{Introduction}

Antenna arrays are widely used in communication systems to obtain desired radiation characteristics. Various techniques for synthesizing arrays are available in literature [1]. Phased array antennas are widely used for conventional beam scanning, beam steering, and adaptive beam forming applications by adapting the excitation amplitude and phase distribution [2]. The limitations associated with the phased array antenna to generate radiation patterns with various stringent designing constraints are cost, size, power consumption, and high complexity. A substantial amount of efforts has been devoted to develop low cost highly reliable phased array antenna since early 1960s. Time modulation applied to linear antenna array is a technique to adapt its radiated power pattern by periodically enabling and disabling the excitations of the individual array elements [3]. Since early 2000s there has been renewed interest in taking up the investigations on this field due to the arrival of the high performance RF switches.
Different time sequences [4-7] were used to control the RF switching. Different optimization strategies have been used in TMAA to synthesize its radiated power pattern $[8,9]$ to realize beam steering [10], beam forming [11-14], null synthesis $[15,16]$, and direction finding [17] without using conventional phase shifters. Application of TMAA in cognitive radio has been analyzed in [14]. In [18], TMAAs has been applied to achieve directional modulation for secure communication. Printed antenna owing to variety of beneficial properties including light weight, low profile, and low cost has become explosively popular and widely investigated in articles [19-22]. Wideband printed antennas utilized in modern wireless communication systems are presented in [23-27]. TMAA as a versatile adequate radiation system for modern wireless applications has increased significantly over recent past.

The presented article proposes TMAA of printed dipoles for beam steering without using phase shifters. The traditional printed dipoles using novel U-shaped ground 


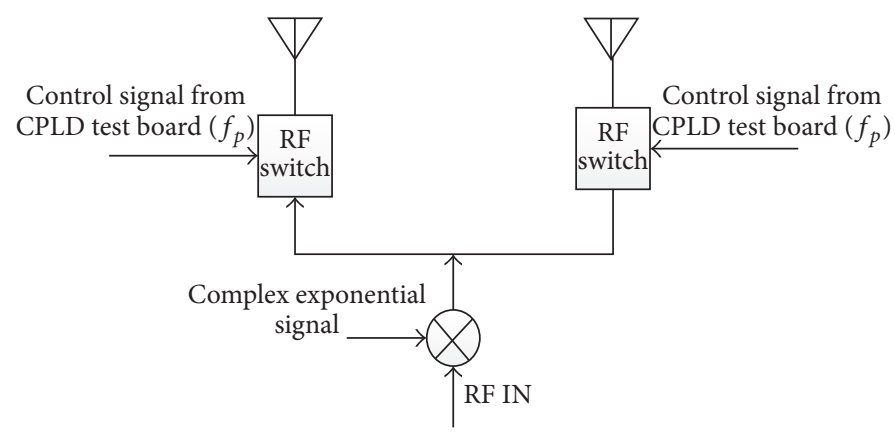

FIGURE 1: Simplified block diagram of the proposed TMAA.

plane and quarter wavelength microstrip via-hole balun are designed at $2.45 \mathrm{GHz}$ and $5.8 \mathrm{GHz}$ inspired by [20]. Introduction of the U-shaped ground plane reflects the electromagnetic waves towards the feeding direction. It improves the reflection coefficient and broadens the bandwidth more effectively than the V-shaped structure used in [20]. The dipoles are connected through a broadband power divider ranging from $2.1 \mathrm{GHz}$ to $7 \mathrm{GHz}$ and PIN diode single pole single throw RF switches. DE is applied to obtain the time sequence to suppress the side band power level (SBL). Application of complex exponential signal steers the beam towards different directions as the switching time sequences of RF switches are modulated. Article [12] has simulated a beamforming network for TMLA using Artificial Bees Colony algorithm. However the present article has successfully implemented the design structure of dual band TM beam steered array using DE.

The antenna structure is rigorously optimized through simulation using CST microwave studio to realize wide bandwidth responses at the two proposed resonances. Experimental testing of the fabricated antenna array shows good agreement with the simulated results.

The rest of the paper is organized as follows. The problem is mathematically formulated in Section 2. Section 3 provides the outline of DE. The design specifications of proposed TMAA are described in Section 4. A set of numerical results is reported and discussed in Section 5. Finally the paper is concluded in Section 6 .

\section{Theoretical Background}

Consider an array of two collinear dipoles with spacing $d$ positioned along the $z$-axis as shown in Figure 1 . Both the array elements are excited using a complex excitation signal $e^{-j 2 \pi f_{p} t}$ and controlled by a high-speed RF switch having $f_{p}$. When a plane wave of frequency $f_{0}$ is incident at an angle $\theta$ with respect to the normal of the array, the far field pattern of the array considering the element pattern is

$$
F(\theta)=e^{j 2 \pi f_{0} t} \sum_{n=1}^{2} I_{n}(t) e^{j \beta d_{n} \cos \theta}\left[\frac{\cos ((\pi / 2) \cos \theta)}{\sin \theta}\right] .
$$

Here $f_{0} \gg f_{p}\left(f_{p}=1 / T_{p}, T_{p}\right.$ is the TM period). $\beta=2 \pi / \lambda$ is the free space wave number, $\lambda=c / f_{0}$ is the wavelength, and $c$ is the speed of light in free space.

$$
I_{n}(t)=\left\{\begin{array}{l}
U_{n}(t), \\
U_{n}(t) e^{-j 2 \pi f_{p} t},
\end{array} \quad \text { for } n=1,2 .\right.
$$

$U_{n}(t)$ is the time switching function of the RF switches modelling the periodic on-off time of the switches. Thus

$$
U_{n}(t)= \begin{cases}1, & k T_{p}+t_{\text {on }} \leq t \leq k T_{p}+t_{\text {on }}+\tau_{n} \\ 0, & \text { otherwise. }\end{cases}
$$

$\tau_{n}$ are the switch-on duration of the RF switches connected to $n$th element and $k$ is an integer. Due to the periodicity of the modulating pulse functions $I_{n}(t)$ can be decomposed into Fourier series with different frequency components, given by

$$
\begin{aligned}
I_{n}(t) & =\sum_{m=-\infty}^{\infty} \Gamma_{n}^{(m)} e^{j 2 \pi m f_{p} t}, \\
\Gamma_{1}^{\langle m\rangle}(t) & =\frac{1}{T_{p}} \int_{0}^{T_{p}} U_{n}(t) e^{-j 2 \pi m f_{p} t} d t, \\
\Gamma_{2}^{\langle m\rangle}(t) & =\frac{1}{T_{p}} \int_{0}^{T_{p}} U_{n}(t) e^{-j 2 \pi(m+1) f_{p} t} d t \\
\Gamma_{n}^{\langle m\rangle} & =\frac{\tau_{n}}{T_{p}} \frac{\sin \left(\pi m f_{p} \tau_{n}\right)}{\pi m f_{p} \tau_{n}} e^{-j \pi(m+n-1) f_{p}\left(2 t_{\mathrm{on}}+\tau_{n}\right)} .
\end{aligned}
$$

Under the hypotheses that $f_{p} \ll f_{0}$ and $\Delta f_{s}<f_{p}$, where $\Delta f_{s}$ is the maximum bandwidth of the received signals, the signal at the working frequency $f_{0}$ can be then extracted by filtering out the SR and eventually the received signal turns out at infinite number of harmonic terms spaced at $m f_{p}(m \in$ $Z$ ) from $f_{0}$. Accordingly, the array factor at $f_{0}$ turns out to be

$$
\begin{aligned}
& F^{\langle 0\rangle}(\theta)=e^{j 2 \pi f_{0} t} \sum_{n=1}^{2} \frac{\tau_{n}}{T_{p}} e^{-j \pi(n-1) f_{p}\left(2 t_{\mathrm{on}}+\tau_{n}\right)} e^{j \beta n d \cos \theta}, \\
& F^{\langle m\rangle}(\theta)=e^{j 2 \pi f_{0} t} \sum_{n=1}^{2} \Gamma_{n}^{\langle m\rangle}(t) e^{j \beta n d \cos \theta} .
\end{aligned}
$$




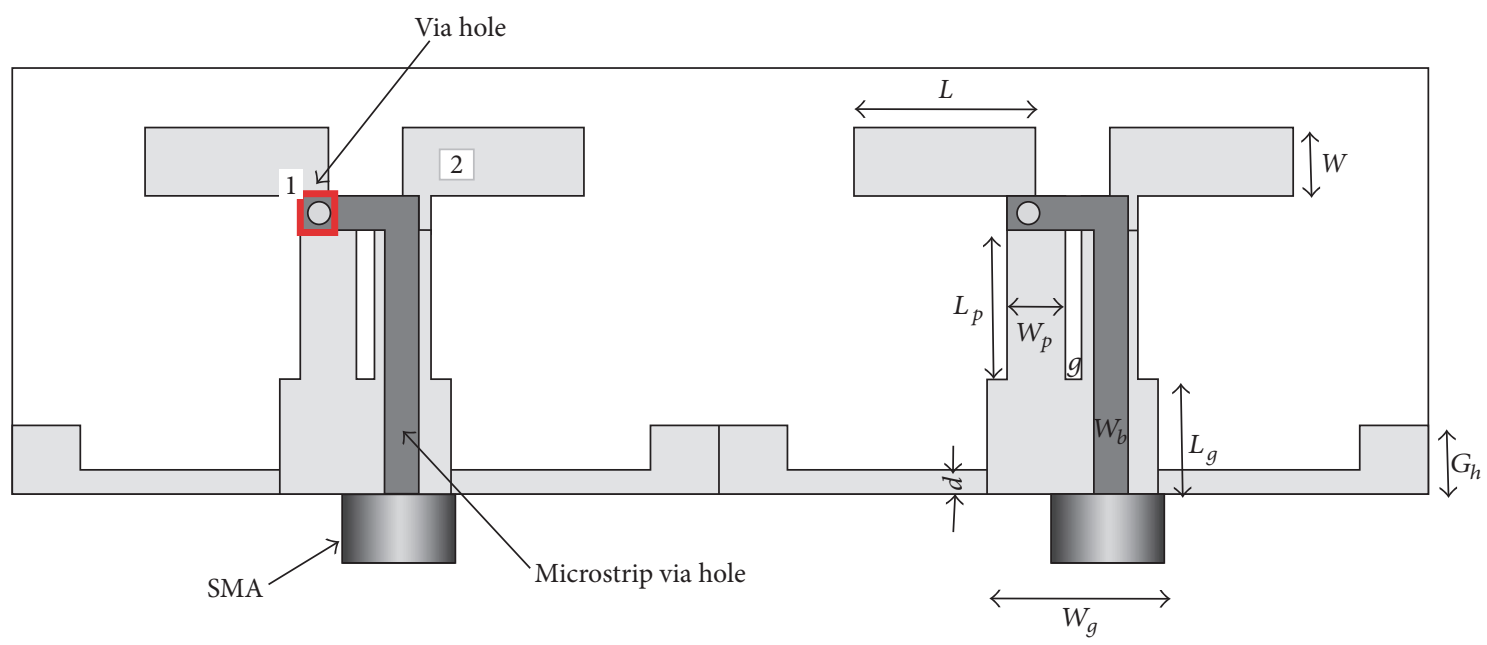

(a)

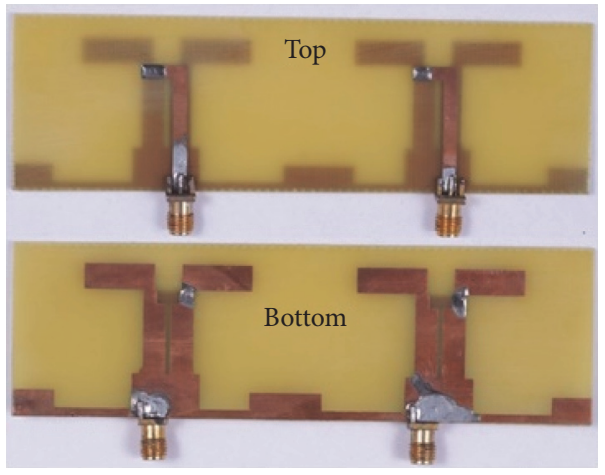

(b)

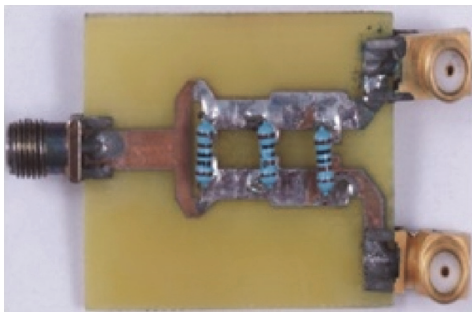

(d)

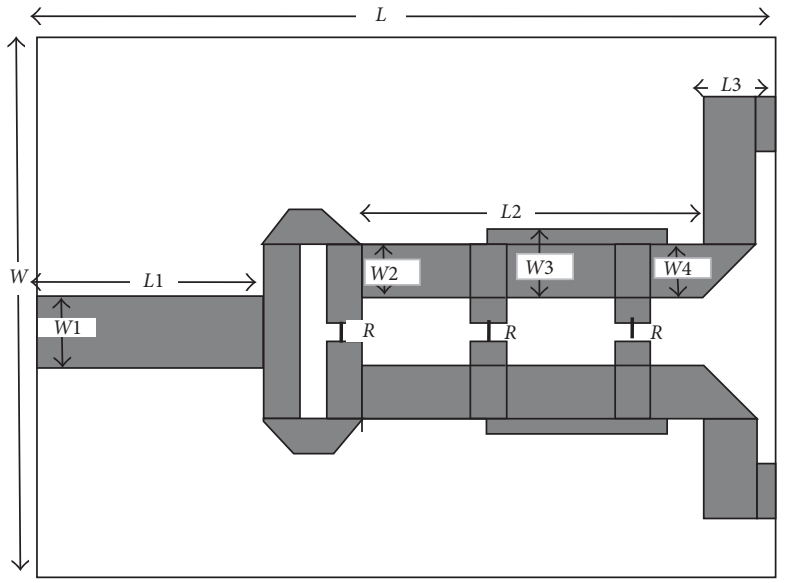

(c)

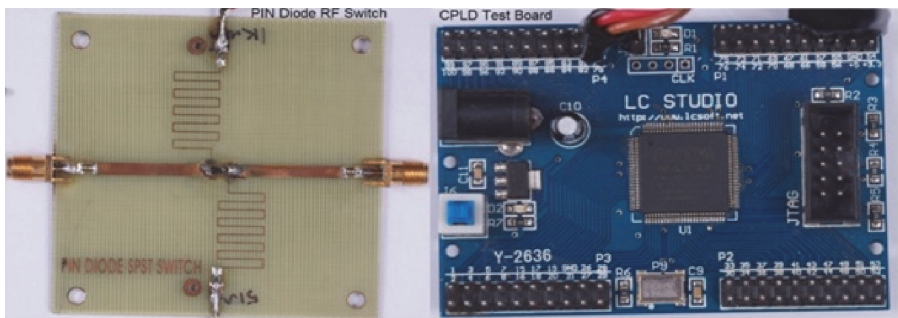

(e)

FIGURE 2: Elements of the TMAA: (a) configuration of the antenna array; (b) prototype of the antenna array; (c) configuration of the power divider; (d) prototype of the power divider; (e) prototype of the RF switch and CPLD test board.

The average power density radiated by the array over $T_{p}$

$$
S(\theta)=\frac{1}{T_{p}} \int_{-T_{p} / 2}^{T_{p} / 2}[\operatorname{Re}\langle F(\theta)\rangle]^{2} d t .
$$

So the total power radiated can be calculated using

$$
P(\theta)=\int_{0}^{2 \pi} \int_{0}^{\pi} S(\theta) \sin \theta d \theta d \phi
$$

Thus using (8), we evaluate the expression of the power radiated at central frequency $\left(P_{0}\right)$ and at the side bands $\left(P_{\mathrm{SR}}\right)$

$$
\begin{aligned}
P_{0} & =2 \pi \sum_{n=1}^{2}\left(\frac{\tau_{n}}{T_{p}}\right)^{2}, \\
P_{\mathrm{SR}} & =2 \pi \sum_{n=1}^{2} \frac{\tau_{n}}{T_{p}}\left(1-\frac{\tau_{n}}{T_{p}}\right) .
\end{aligned}
$$




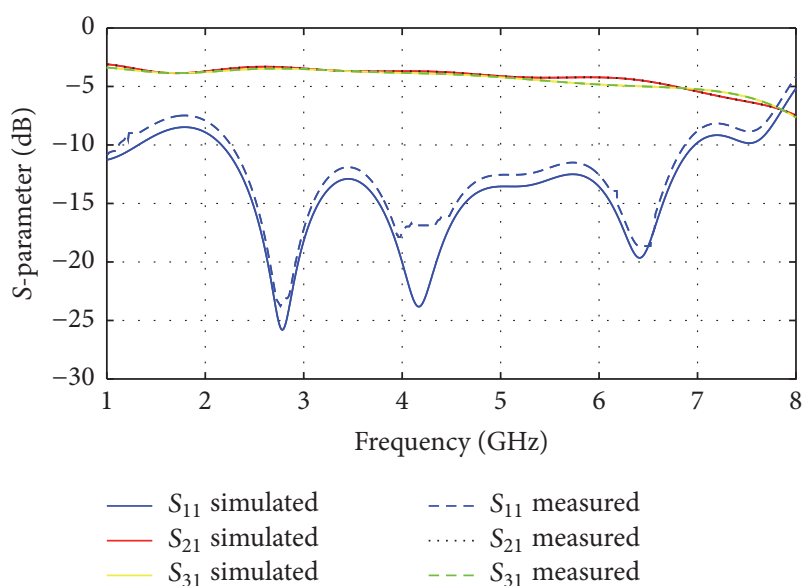

(a)

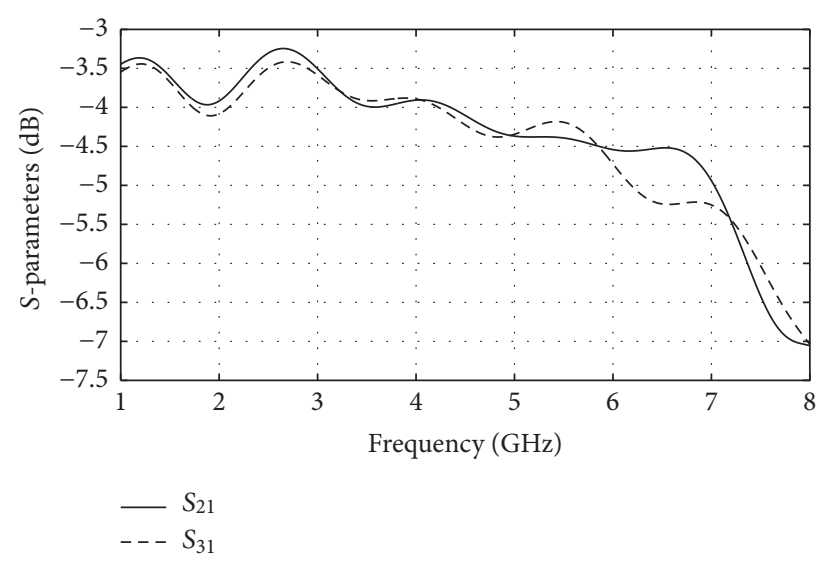

(b)

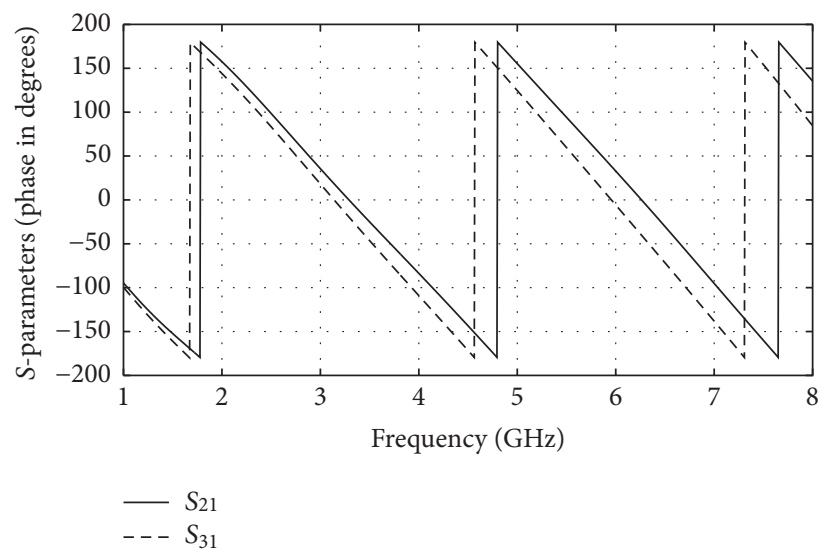

(c)

FIgURE 3: (a) Simulated and measured scattering parameters of power divider. (b) Magnitude of simulated $S_{21}$ and $S_{31}$ parameter. (c) Phase of simulated $S_{21}$ and $S_{31}$ parameter.

So the dynamic efficiency of the array is

$$
\eta=\frac{\tau_{1}^{2}+\tau_{2}^{2}}{T_{p}\left(\tau_{1}+\tau_{2}\right)-\tau_{1}^{2}-\tau_{2}^{2}} .
$$

In order to suppress the SLL and enhance the dynamic efficiency, the DE algorithm is applied as the global optimization method. To achieve the design goal the following fitness function is formulated for minimization over iterations using $\mathrm{DE}$

$$
\operatorname{Fitness}\left(t_{\mathrm{on}}, \tau_{n}\right)=k_{1} \mathrm{SLL}+k_{2}\left(\frac{1}{\eta}\right),
$$

while SBL at the first sideband is not allowed to rise beyond $-25 \mathrm{~dB}$. The constants $k_{1}$ and $k_{2}$ are the corresponding weighing factors of SLL and dynamic efficiency, respectively. In the designing problem, equal weightage $\left(k_{1}=\right.$ $k_{2}=1$ ) of both the parameters is considered. The switchon time $\left(t_{\text {on }}\right)$ and switch-on duration $\left(\tau_{n}\right)$ of each element are considered as population vectors and varied in order to minimize the fitness function.

\section{Differential Evolution}

Differential Evolution (DE) proposed by Storn and Price $[28,29]$ is well known population based simple and efficient method for global optimization. DE algorithm consists of the following basic steps: initialization, mutation, crossover, selection, and termination.

(1) Initialization of Population. DE searches for a global optimum within a continuous search space of dimension $D$. Generate $K D$-dimensional population of target vectors for each generation $G$.

$$
\begin{aligned}
\vec{A}_{i, G}=\left[a_{i, G}^{1}, a_{i, G}^{2}, a_{i, G}^{3}, \ldots, a_{i, G}^{D}\right], & \\
& \text { where } i=1,2,3, \ldots, K .
\end{aligned}
$$

Target vectors with better results may be found in a definite region of search space with maximum and minimum bounds in each dimension as

$$
\begin{aligned}
& \vec{A}_{\max }=\left[a_{\max }^{1}, a_{\max }^{2}, \ldots, a_{\max }^{D}\right], \\
& \vec{A}_{\min }=\left[a_{\min }^{1}, a_{\min }^{2}, \ldots, a_{\min }^{D}\right] .
\end{aligned}
$$




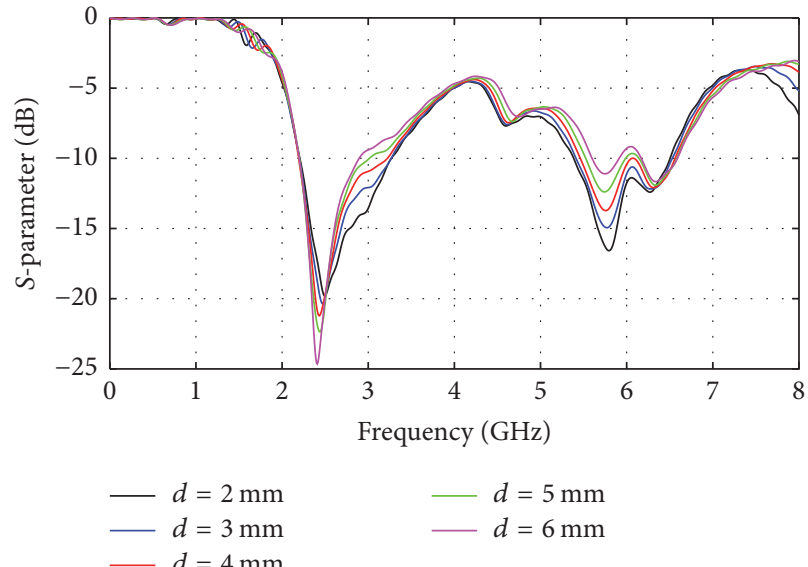

(a)

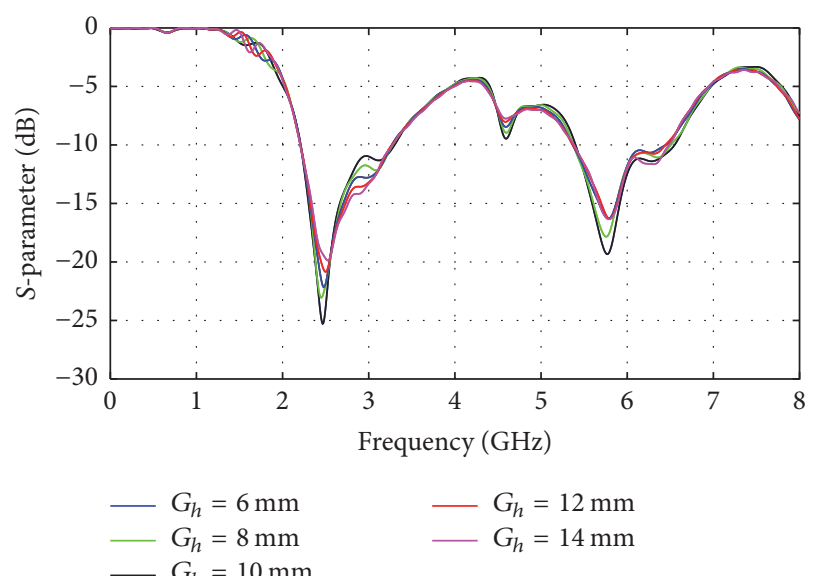

(b)

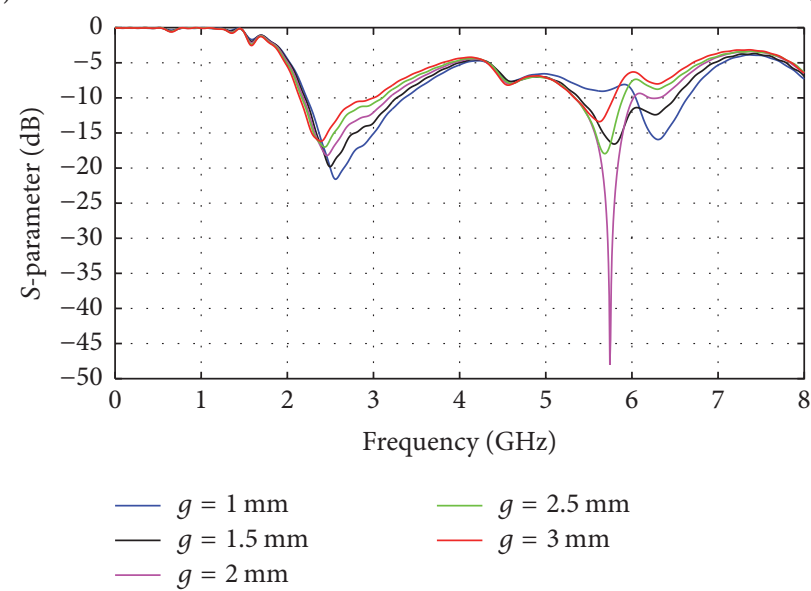

(c)

Figure 4: Optimized return loss of antenna array: (a) $S_{11}$ for different $d$; (b) $S_{11}$ for different $G_{h}$; (c) $S_{11}$ for different $g$.

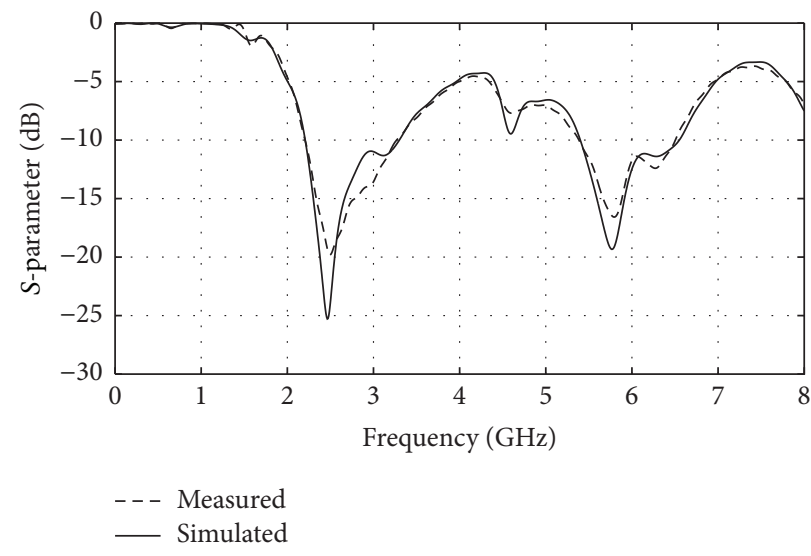

FiguRE 5: Simulated and measured return loss of antenna array.

The $j$ th component of the $i$ th vector is initialized as

$$
\begin{aligned}
a_{i, 0}^{j}=a_{\min }^{j}+\operatorname{rand}_{i}^{j}(0,1) \cdot\left(a_{\max }^{j}-a_{\min }^{j}\right), & \\
& j \in\{1,2,3, \ldots, D\},
\end{aligned}
$$

where $\operatorname{rand}_{i}^{j}(0,1)$ is a uniformly distributed random number lying between 0 and 1 .
(2) Mutation. After initialization, a donor vector $\vec{M}_{i, G}$ corresponding to best population member $\vec{A}_{\text {best, } G}$ in the current generation is created through mutation.

$$
\vec{M}_{i, G}=\vec{A}_{\text {best }, G}+F \cdot\left(\vec{A}_{r_{1}^{i}, G}-\vec{A}_{r_{2}^{i}, G}\right) .
$$

The indices $r_{1}^{i}$ and $r_{2}^{i}$ are mutually exclusive integers and randomly chosen from the range $(1,2, \ldots, K) . F$ is called scaling 


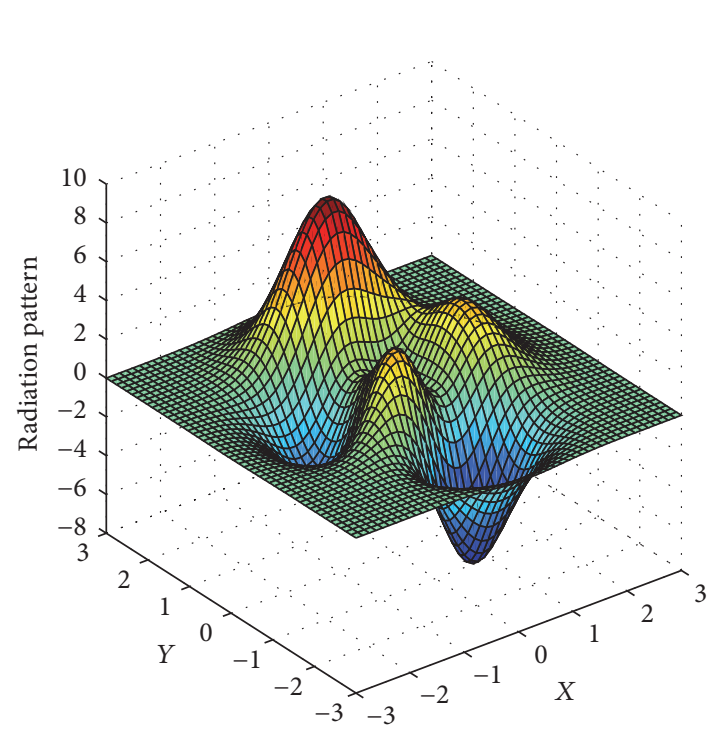

(a) $3 \mathrm{D}$ radiation pattern plot

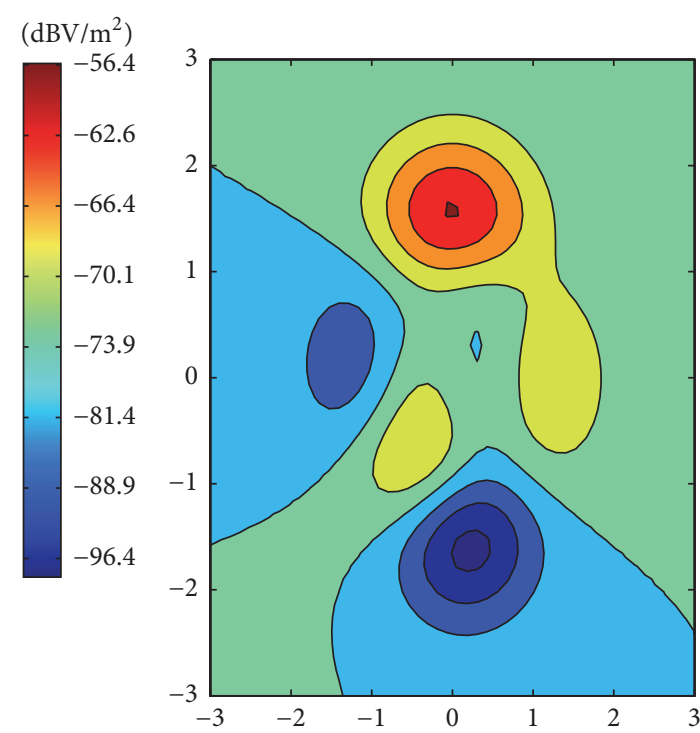

(b) Contour plot

FIGURE 6: Optimized radiation pattern at centre frequency $2.45 \mathrm{Ghz}$.

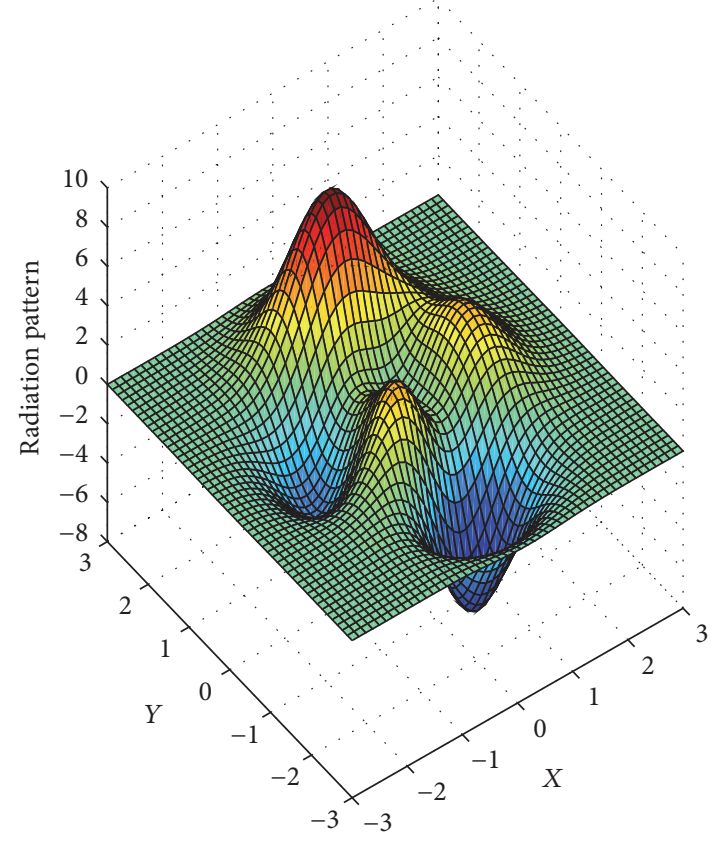

(a) $3 \mathrm{D}$ radiation pattern plot

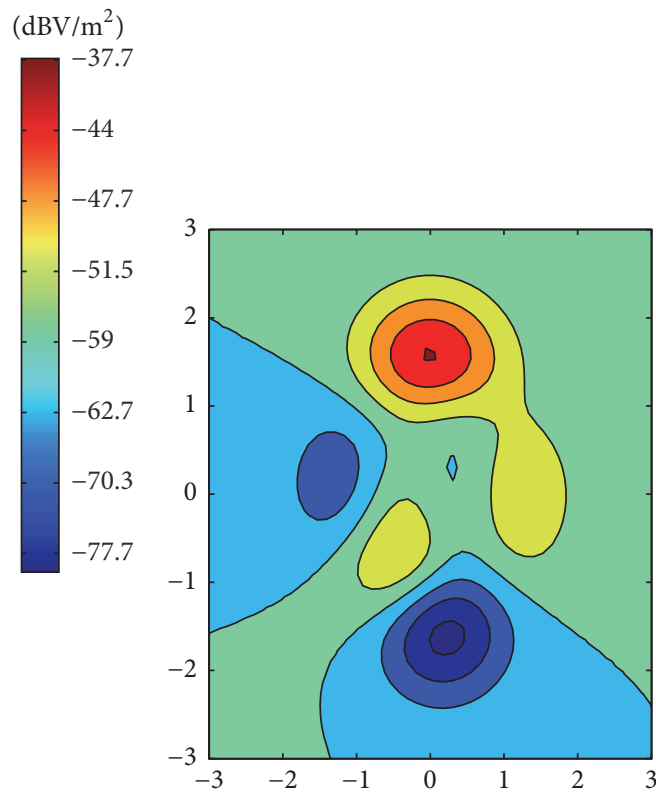

(b) Contour plot

FIGURE 7: Optimized radiation pattern at centre frequency $5.8 \mathrm{Ghz}$.

factor which will be tuned according to the fitness function generated by each vector. $\vec{A}_{\text {best, },}$ is the best individual vector with minimum fitness value in the population at generation G.

(3) Crossover. In crossover operation the donor vector mixes its components with the target vector $\vec{A}_{i, G}$ to obtain the trial vector of the same index denoted as $\vec{T}_{i, G}=$ $\left[t_{i, G}^{1}, t_{i, G}^{2}, t_{i, G}^{3}, \ldots, t_{i, G}^{D}\right]$. The trial vector created is

$$
t_{i, G}^{j}= \begin{cases}m_{i, G}^{j}, & \text { if }\left(\operatorname{rand}_{i}^{j}(0,1) \leq \mathrm{CR} \text { or } j=j_{\text {rand }}\right), \\ a_{i, G}^{j}, & \text { otherwise }\end{cases}
$$




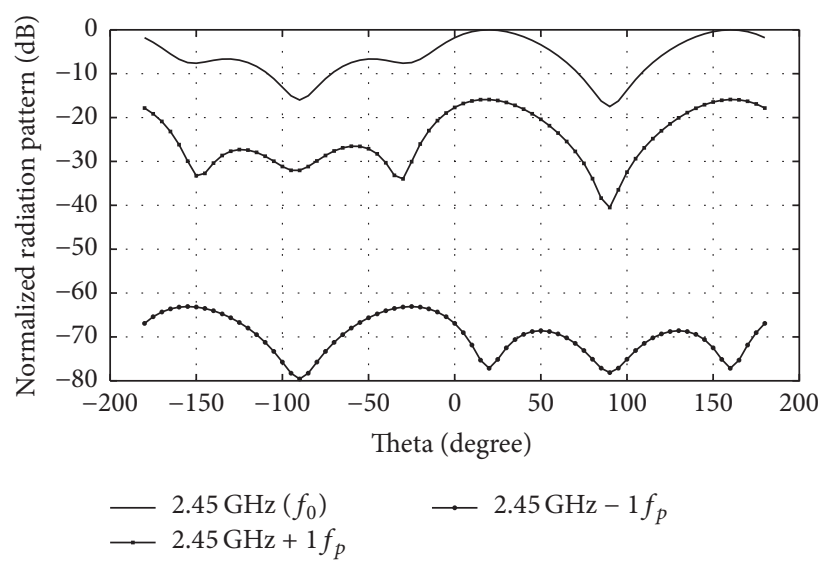

FIGURE 8: Radiation pattern at centre frequency $2.45 \mathrm{Ghz}$ and sidebands.

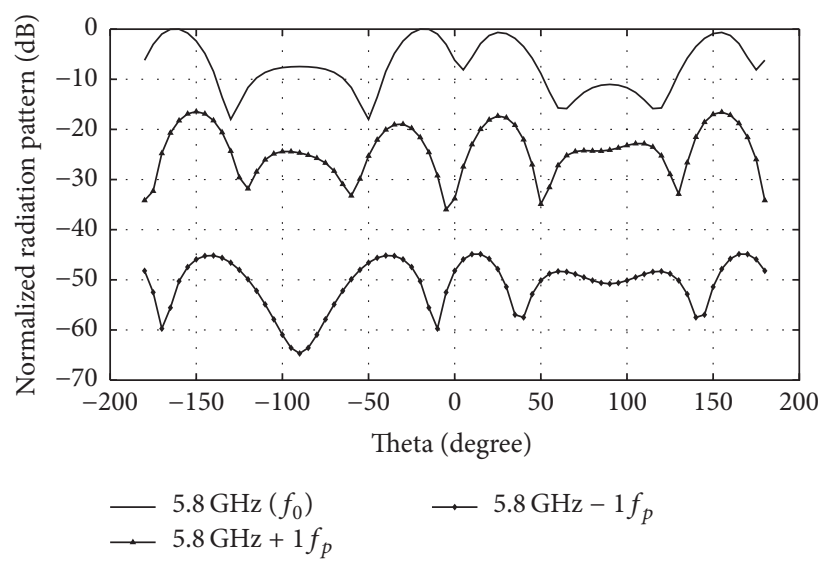

FIgURE 9: Radiation pattern at centre frequency $5.8 \mathrm{Ghz}$ and sidebands.

where CR is the crossover rate belongs the interval $(0,1)$. $j_{\text {rand }} \in[1,2, \ldots, D]$ is a randomly chosen index which differentiate trial vector $\vec{T}_{i, G}$ from its corresponding target vector $\vec{A}_{i, G}$.

(4) Selection. Selection is introduced to determine which of the target or trial vectors survives to the next generation. If the fitness value of the trial vector is equal to or less than that of the corresponding target vector then the trial vector is selected for next generation; otherwise the target vector is selected for next generation.

(5) Termination. If termination condition is not satisfied the execution is returned to Step (2); otherwise it is terminated.

\section{Prototype Design}

A prototype of the overall system is implemented and presented in this section. The overall system consists of 2element printed dipole antenna array, RF switches, pulse generator, power divider, and an analog multiplier. The antenna array, power divider, and RF switches are printed on the FR4 dielectric material of dielectric constant 4.4 and thickness $1.6 \mathrm{~mm}$. The configurations and prototype of the antenna array and power divider are shown in Figure 2 and the dimensions are presented in Table 1 . The overall dimension of the antenna array is $136 \mathrm{~mm} \times 37 \mathrm{~mm}$. The $\mathrm{RF}$ switch is realized by connecting a series capacitor, $10 \mathrm{nf}$ before and after the pin diode, BAR63-02. Capacitors are connected to provide the RF connectivity and to prevent the dc. The prototype of the RF switch is shown in Figure 2(e). A rectangular pulse train of $3 \mathrm{~V}$ at a repetition frequency of $1 \mathrm{MHz}$ is applied to bias the PIN diode. The CPLD test board (Figure 2(e)) is programmed to generate the desired rectangular pulse and can be tuned for different time sequences. The antenna array, RF switches, and power divider are connected through $50 \Omega$ SMA male/female connectors. The complex exponential signal and RF signals are provided through the signal generator and RF source.

\section{Results and Discussion}

The proposed steering technique is experimented with an array prototype comprising of two microstrip fed printed 
TABLE 1: Structural parameters of dipole antenna array and power divider.

\begin{tabular}{|c|c|c|c|c|}
\hline \multirow{2}{*}{ Part of dipole } & \multicolumn{2}{|c|}{ Dipole antenna array $(136 \mathrm{~mm} \times 37 \mathrm{~mm})$} & \multicolumn{2}{|c|}{ Power divider $(41 \mathrm{~mm} \times 30 \mathrm{~mm})$} \\
\hline & Parameter & Dimension & Parameter & Dimension \\
\hline \multirow{3}{*}{ PCB substrate } & Thickness & $1.6 \mathrm{~mm}$ & Substrate thickness & $1.6 \mathrm{~mm}$ \\
\hline & $\varepsilon_{r}$ & 4.4 & $\varepsilon_{r}$ & 4.4 \\
\hline & $\tan \delta$ & 0.0018 & $\tan \delta$ & 0.0018 \\
\hline \multirow{6}{*}{ Ground plane } & $d$ & $2 \mathrm{~mm}$ & $L$ & $41 \mathrm{~mm}$ \\
\hline & $G_{h}$ & $6 \mathrm{~mm}$ & $W$ & $30 \mathrm{~mm}$ \\
\hline & $L_{g}$ & $10 \mathrm{~mm}$ & $L 1$ & $12.56 \mathrm{~mm}$ \\
\hline & $W_{g}$ & $15 \mathrm{~mm}$ & $L 2$ & $19 \mathrm{~mm}$ \\
\hline & $L_{p}$ & $13 \mathrm{~mm}$ & $L 3$ & $4 \mathrm{~mm}$ \\
\hline & $W_{p}$ & $5 \mathrm{~mm}$ & $W 1$ & $4 \mathrm{~mm}$ \\
\hline \multirow{2}{*}{ Dipole arm } & $L$ & $16 \mathrm{~mm}$ & $W 2$ & $3.057 \mathrm{~mm}$ \\
\hline & $W$ & $6 \mathrm{~mm}$ & $W 3$ & $3.83 \mathrm{~mm}$ \\
\hline \multirow{2}{*}{ Microstrip balun } & $W_{b}$ & $3 \mathrm{~mm}$ & $W 4$ & $2.947 \mathrm{~mm}$ \\
\hline & Via-hole radius & $1 \mathrm{~mm}$ & $R$ & $100 \Omega$ \\
\hline
\end{tabular}
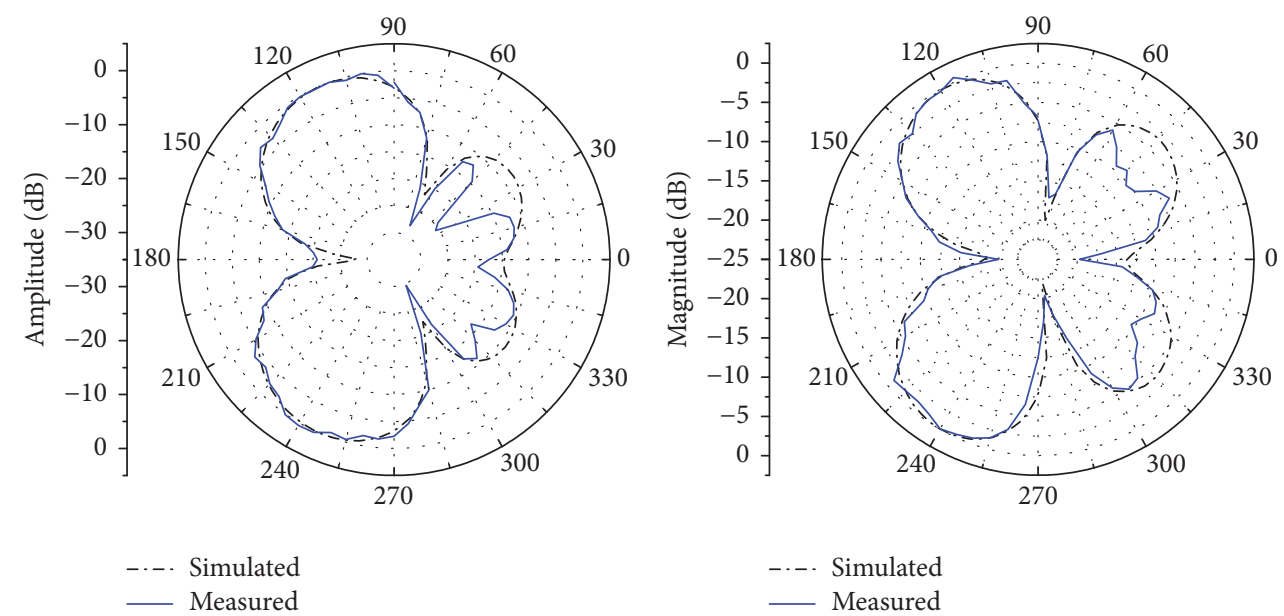

(a)

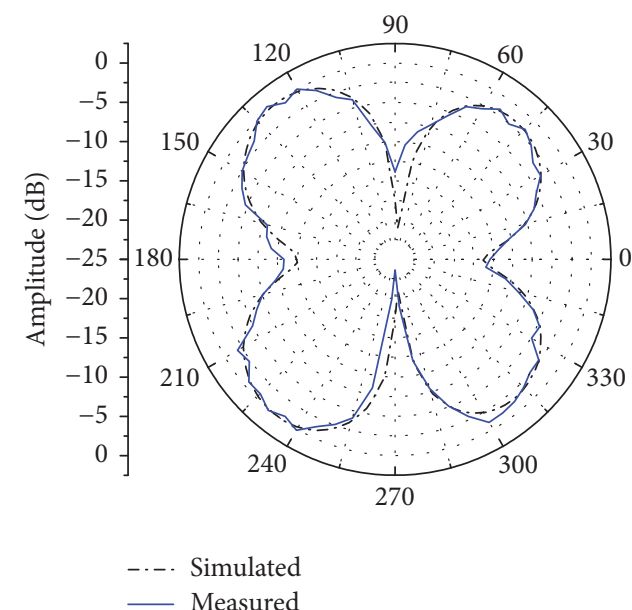

(b)

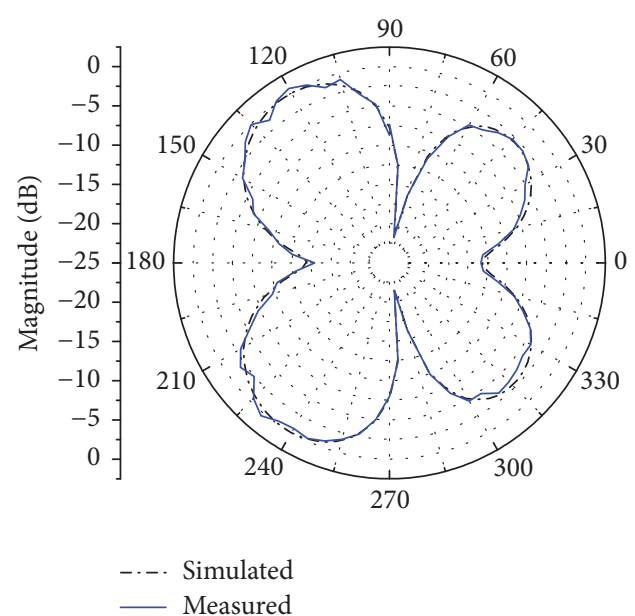

(c)

(d)

FIGURE 10: Simulated and measured radiation pattern for different values of $t_{02}$ at $2.45 \mathrm{GHz}$. (a) $t_{02}=0 \mu \mathrm{sec}$. (b) $t_{02}=0.125 \mu$ sec. (c) $t_{02}=0.25 \mu \mathrm{sec}$. (d) $t_{02}=0.375 \mu \mathrm{sec}$. 


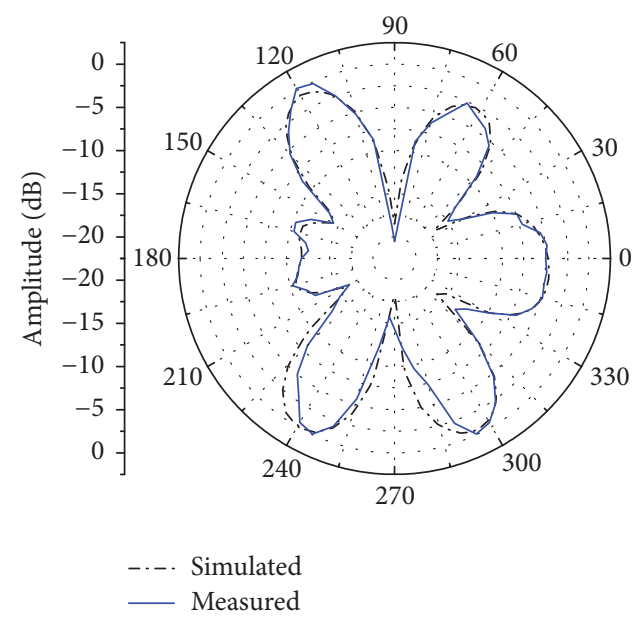

(a)

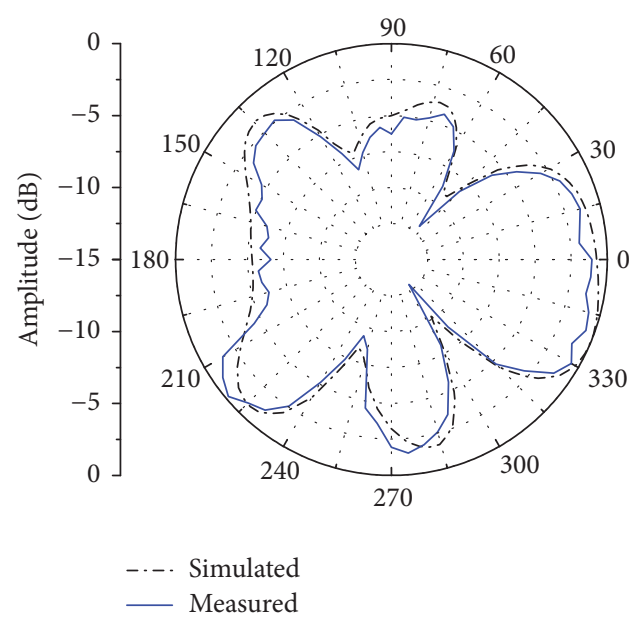

(b)

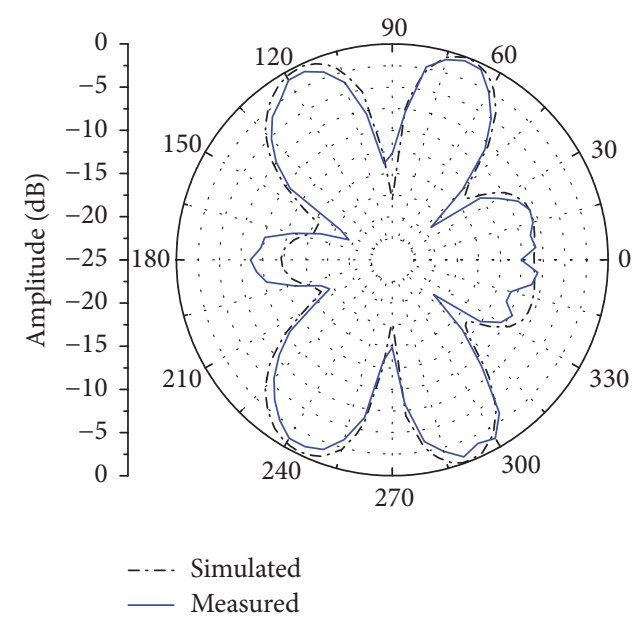

(c)

FIGURE 11: Simulated and measured radiation pattern for different values of $t_{02}$ at $5.8 \mathrm{GHz}$. (a) $t_{02}=0 \mu \mathrm{sec}$. (b) $t_{02}=0.125 \mu \mathrm{sec}$. (c) $t_{02}=$ $0.375 \mu \mathrm{sec}$.

dipoles for dual band operation at $2.45 \mathrm{GHz}$ and $5.8 \mathrm{GHz}$, as shown in Figure 2. The structure of the printed dipoles is designed to provide good impedance matching over the operating frequency bands. The feed network of the proposed TMAA is composed of an ultra-wideband power divider covering $2.1 \mathrm{GHz}$ to $7 \mathrm{GHz}$ (Figure 3(a)) and RF switches. The antenna, power divider, and RF switch are optimized using EM simulator and CST microwave studio and tested using the Network Analyzer E5071C of Agilent Technologies. The prototype of the power divider is fabricated and the scattering parameters are presented in Figure 3. Figure 3(b) shows that the magnitude of $S_{21}$ and $S_{31}$ is marginally deviated from $-3 \mathrm{~dB}$ ensuring almost equal power division at $2.45 \mathrm{GHz}$. However it becomes almost $-4.5 \mathrm{~dB}$ at $5.8 \mathrm{GHz}$. Figure 3(c) presents a small phase difference between port 2 and port 3 over the bandwidth and ensures almost equal power splitting. The structure of front and the back side of the broadband power divider is identical allowing equal current distribution at both sides. The dimensions of the ground plane, $d$ and $G_{h}$, and the gap $g$ between the two arms of the bottom ground layer are rigorously studied in order to obtain optimized design parameters, as shown in Figure 4. The prototype of the antenna array is fabricated and presented in Figure 5. The on state insertion loss and off state isolation of the RF switch are studied and found $0.6 \mathrm{~dB}$ and $25 \mathrm{~dB}$, respectively. The return loss and bandwidth of proposed prototype TMAA at both the frequencies are tabulated in Table 2.

Firstly, the on time duration $\left(\tau_{n}\right)$ and switch-on instance $\left(t_{\text {on }}\right)$ of the rectangular pulses applied to RF switches are optimized using DE in order to obtain radiation pattern with suppressed SLL and enhanced dynamic efficiency at both the operating frequencies. To achieve $\eta \geq 98 \%$, the optimized time sequences of the input pulse train are set at $\tau_{1}=0.6035$, $\tau_{2}=0.2548, t_{01}=0$, and $t_{02}=0.1226$ using programmed CPLD to modulate the input excitation according to (7). The radiation pattern obtained using time modulated excitation distribution is shown in the corresponding contour and Cartesian plot given in Figures 6, 7, 8, and 9 at $2.45 \mathrm{GHz}$ and $5.8 \mathrm{GHz}$, respectively. The DE optimized simulated radiation patterns, presented in Figures 8 and 9, confirm that the SBL 
TABLE 2: Results of proposed prototype antenna array.

\begin{tabular}{lcccc}
\hline Prototype & Frequency & Parameter & Simulated value & Measured value \\
\hline & \multirow{2}{*}{$2.5 \mathrm{GHz}$} & $S_{11}$ & $-25.28 \mathrm{~dB}$ & $-20.2 \mathrm{~dB}$ \\
Proposed array of two printed dipoles with U-shaped ground & & Bandwidth & $1.21 \mathrm{GHz}$ & $1.2 \mathrm{GHz}$ \\
& \multirow{2}{*}{$5.8 \mathrm{GHz}$} & $S_{11}$ & $-19.33 \mathrm{~dB}$ & $-16.99 \mathrm{~dB}$ \\
& & Bandwidth & $1.11 \mathrm{GHz}$ & $1.02 \mathrm{GHz}$ \\
\hline
\end{tabular}

TABLE 3: Desired and obtained SLL.

\begin{tabular}{lcc}
\hline Design parameter & \multicolumn{2}{c}{ Side lobe level $(\mathrm{dB})$} \\
& Desired & Obtained \\
\hline $2.45 \mathrm{GHz}$ & -8 & -7.1 \\
$f_{0}(2.45 \mathrm{GHz})$ & $\leq-25$ & -26.28 \\
$f_{0}+f_{p}(2.451 \mathrm{GHz})$ & $\mathrm{NA}$ & -68.34 \\
$f_{0}-f_{p}(2.449 \mathrm{GHz})$ & & \\
$5.8 \mathrm{GHz}$ & -8 & -7.68 \\
$f_{0}(5.8 \mathrm{GHz})$ & $\leq-25$ & -24.53 \\
$f_{0}+f_{p}(5.801 \mathrm{GHz})$ & $\mathrm{NA}$ & -48.142 \\
$f_{0}-f_{p}(5.799 \mathrm{GHz})$ & & \\
\hline
\end{tabular}

are lowered significantly at the first two sidebands for both the cases. Table 3 gives the desired and obtained values of SLL and SBL of the radiation patterns, shown in Figures 8 and 9 at centre frequency as well as first two sidebands. The beam steered polar radiation patterns ( $E$ plane) at the centre frequencies without considering SLL constraints are shown in Figures 10 and 11. In this case, the input pulse train are set at $\tau_{1}=1, \tau_{2}=\left(1-t_{02}\right), t_{01}=0$, and $t_{02}$ is calculated using (7) to steer the main beam at different directions and implemented with the programmed CPLD. To ensure the flawless radiation pattern, the measurements are taken in a shielded surrounding.

\section{Conclusion}

A prototype TMAA using printed dipoles operating at $2.45 \mathrm{GHz}$ and $5.8 \mathrm{GHz}$ is proposed for beam steering. Parametric optimization of the proposed array utilizing modified ground structure is done to obtain wider impedance bandwidth. A complex exponential signal applied through the power divider and PIN diode RF switches are used to excite the phase differences between dipoles. DE has been used to suppress the sideband radiations increasing the dynamic efficiency of the radiation pattern steered at different directions. The modulation of the switching sequences of the rectangular pulses controls the relative phase difference between elements and steers the beam in different directions without phase shifter. Experimental validation confirms the effectiveness of the proposed technique over conventional phased array antenna.

\section{Competing Interests}

The authors declare that there is no conflict of interests regarding the publication of this paper.

\section{References}

[1] W. L. Stutzman and G. A. Thiele, Antenna Theory and Design, Wiley, Hoboken, NJ, USA, 3rd edition, 2013.

[2] R. J. Mailloux, Phased Array Antenna Handbook, Artech House, Norwood, Mass, USA, 2nd edition, 2005.

[3] B. Basu and G. K. Mahanti, "Beam reconfiguration of linear array of parallel dipole antennas through switching with real excitation voltage distribution," Annales des Telecommunications/Annals of Telecommunications, vol. 67, no. 5-6, pp. 285293, 2012.

[4] Q. Zhu, S. Yang, L. Zheng, and Z. Nie, "Design of a low sidelobe time modulated linear array with uniform amplitude and subsectional optimized time steps," IEEE Transactions on Antennas and Propagation, vol. 60, no. 9, pp. 4436-4439, 2012.

[5] Y. Tong and A. Tennant, "Sideband level suppression in timemodulated linear arrays using modified switching sequences and fixed bandwidth elements," Electronics Letters, vol. 48, no. 1, pp. 10-11, 2012.

[6] E. T. Bekele, L. Poli, P. Rocca, M. D’Urso, and A. Massa, "Pulse-shaping strategy for time modulated arrays-analysis and design," Institute of Electrical and Electronics Engineers. Transactions on Antennas and Propagation, vol. 61, no. 7, pp. 3525-3537, 2013.

[7] A.-M. Yao, W. Wu, and D.-G. Fang, "Single-sideband timemodulated phased array," IEEE Transactions on Antennas and Propagation, vol. 63, no. 5, pp. 1957-1968, 2015.

[8] M. A. Mangoud, H. M. Elragal, and M. T. Alshara, "Design of time modulated concentric circular and concentric hexagonal antenna array using hybrid enhanced particle swarm optimisation and differential evolution algorithm," IET Microwaves, Antennas and Propagation, vol. 8, no. 9, pp. 657-665, 2014.

[9] J. Euziere, R. Guinvarc'h, B. Uguen, and R. Gillard, “Optimization of sparse time-modulated array by genetic algorithm for radar applications," IEEE Antennas and Wireless Propagation Letters, vol. 13, pp. 161-164, 2014.

[10] J. Yang, W. Li, and X. Shi, "Phase modulation technique for fourdimensional arrays," IEEE Antennas and Wireless Propagation Letters, vol. 13, pp. 1393-1396, 2014.

[11] Y. Tong and A. Tennant, "A two-channel time modulated linear array with adaptive beamforming," IEEE Transactions on Antennas and Propagation, vol. 60, no. 1, pp. 141-147, 2012.

[12] R. Ruchi, A. Nandi, and B. Basu, "Design of beam forming network for time-modulated linear array with artificial bees colony algorithm," International Journal of Numerical Modelling: Electronic Networks, Devices and Fields, vol. 28, no. 5, pp. 508-521, 2015.

[13] C. He, X. Liang, B. Zhou, J. Geng, and R. Jin, "Space-division multiple access based on time-modulated array," IEEE Antennas and Wireless Propagation Letters, vol. 14, pp. 610-613, 2015.

[14] P. Rocca, Q. Zhu, E. T. Bekele, S. Yang, and A. Massa, "4-D arrays as enabling technology for cognitive radio systems," IEEE 
Transactions on Antennas and Propagation, vol. 62, no. 3, pp. 1102-1116, 2014.

[15] K. Guney and S. Basbug, "Null synthesis of time-modulated circular antenna arrays using an improved differential evolution algorithm," IEEE Antennas And Wireless Propagation Letters, vol. 12, pp. 817-820, 2013.

[16] G. Bogdan, P. R. Bajurko, and Y. Yashchyshyn, "Null-steering in two-element time modulated linear antenna array through pulse-delay approach," in Proceedings of the 20th International Conference on Microwaves, Radar and Wireless Communications (MIKON '14), Gdansk, Poland, June 2014.

[17] C. He, X. Liang, Z. Li, J. Geng, and R. Jin, "Direction finding by time-modulated array with harmonic characteristic analysis," IEEE Antennas and Wireless Propagation Letters, vol. 14, pp. 642-645, 2015.

[18] Q. Zhu, S. Yang, R. Yao, and Z. Nie, "Directional modulation based on 4-D antenna arrays," IEEE Transactions on Antennas and Propagation, vol. 62, no. 2, pp. 621-628, 2014.

[19] I. J. Bahl and P. Bhartia, Microstrip Antennas, Artech House, Norwood, Mass, USA, 2003.

[20] Z. G. Fan, S. Qiao, J. T. Huangfu, and L. X. Ran, "A miniaturized printed dipole antenna with V-shaped ground for $2.45 \mathrm{GHz}$ RFID readers," Progress in Electromagnetics Research, vol. 71, pp. 149-158, 2007.

[21] M. Li and K.-M. Luk, "A low-profile unidirectional printed antenna for millimeter-wave applications," IEEE Transactions on Antennas and Propagation, vol. 62, no. 3, pp. 1232-1237, 2014.

[22] C. Reig and E. Ávila-Navarro, "Printed antennas for sensor applications: a review," IEEE Sensors Journal, vol. 14, no. 8, pp. 2406-2418, 2014.

[23] A. R. Behera and A. R. Harish, "A novel printed wideband dipole antenna," IEEE Transactions on Antennas and Propagation, vol. 60, no. 9, pp. 4418-4422, 2012.

[24] K. Xu, Z. Zhu, H. Li, J. Huangfu, C. Li, and L. Ran, "A printed single-layer UWB monopole antenna with extended ground plane stubs," IEEE Antennas and Wireless Propagation Letters, vol. 12, pp. 237-240, 2013.

[25] M. Zomorrodi and N. Chandra Karmakar, "Chipless RFID reader: low-cost wideband printed dipole array antenna," IEEE Antennas and Propagation Magazine, vol. 57, no. 5, pp. 18-29, 2015.

[26] M. S. Ellis, Z. Zhao, J. Wu, Z. Nie, and Q. H. Liu, "Small planar monopole ultra-wideband antenna with reduced ground plane effect," IET Microwaves, Antennas \& Propagation, vol. 9, no. 10, pp. 1028-1034, 2015.

[27] M. S. Khan, A.-D. Capobianco, A. Naqvi, B. Ijaz, S. Asif, and B. D. Braaten, "Planar, compact ultra-wideband polarisation diversity antenna array," IET Microwaves, Antennas \& Propagation, vol. 9, no. 15, pp. 1761-1768, 2015.

[28] R. M. Storn, K. V. Price, and J. A. Lampinen, Differential Evolution-A Practical Approach to Global Optimization, Natural Computing Series, Springer, Berlin, Germany, 2005.

[29] S. Das, A. Abraham, U. K. Chakraborty, and A. Konar, "Differential evolution using a neighborhood-based mutation operator," IEEE Transactions on Evolutionary Computation, vol. 13, no. 3, pp. 526-553, 2009. 


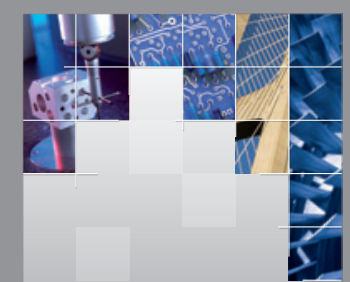

\section{Enfincering}
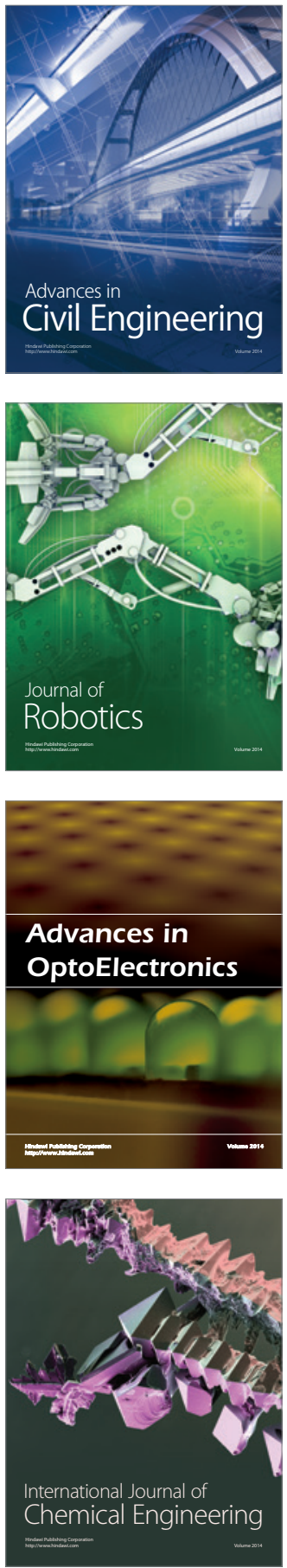

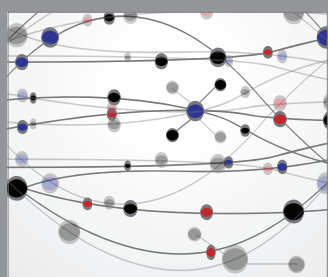

The Scientific World Journal

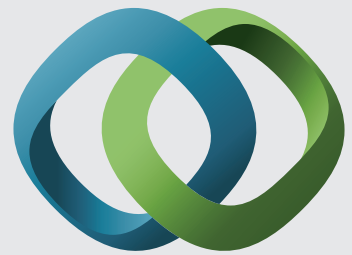

\section{Hindawi}

Submit your manuscripts at

https://www.hindawi.com
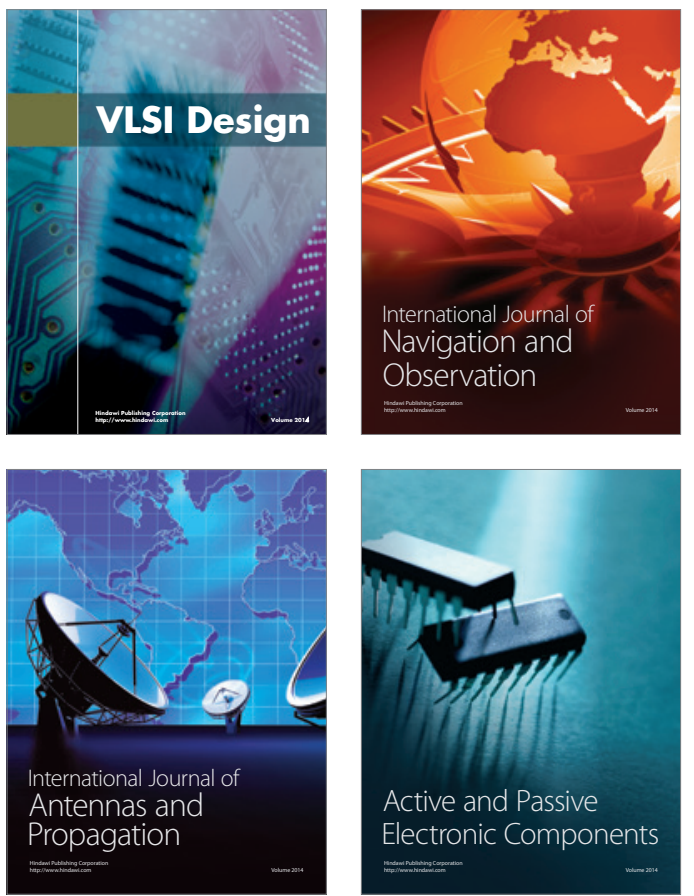
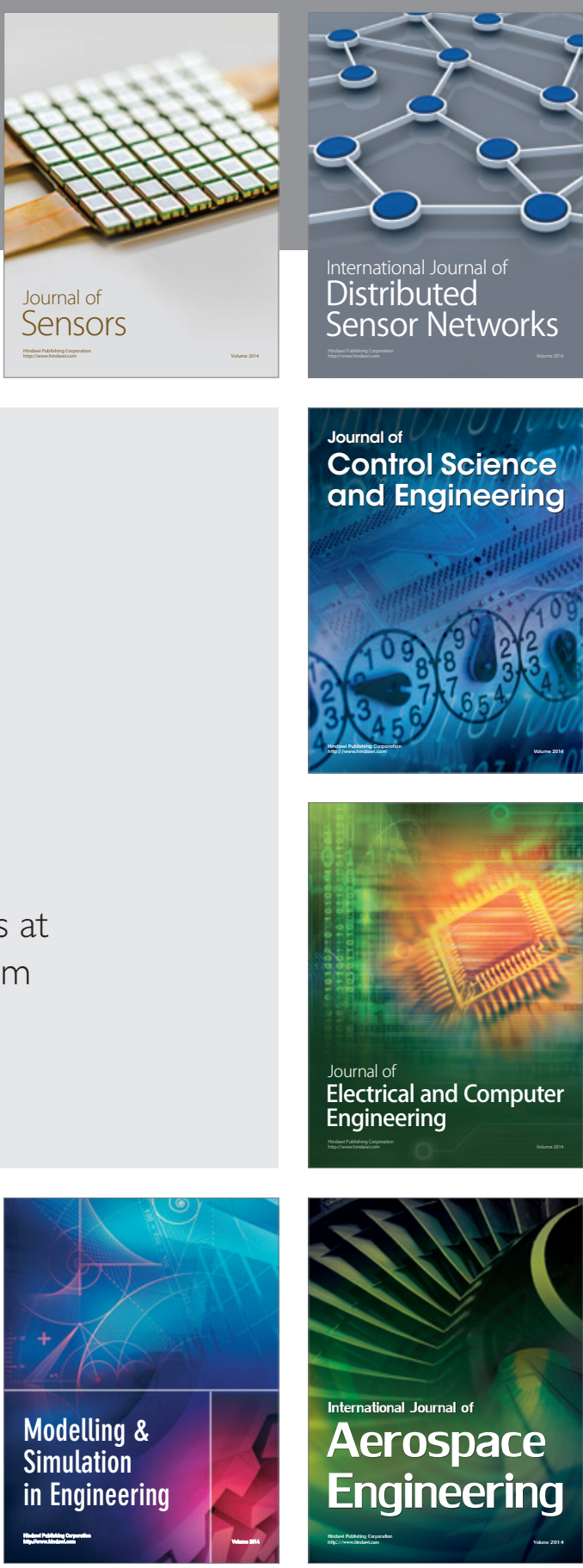

International Journal of

Distributed

Sensor Networks

$-$

Joumal of

Control Science

and Engineering
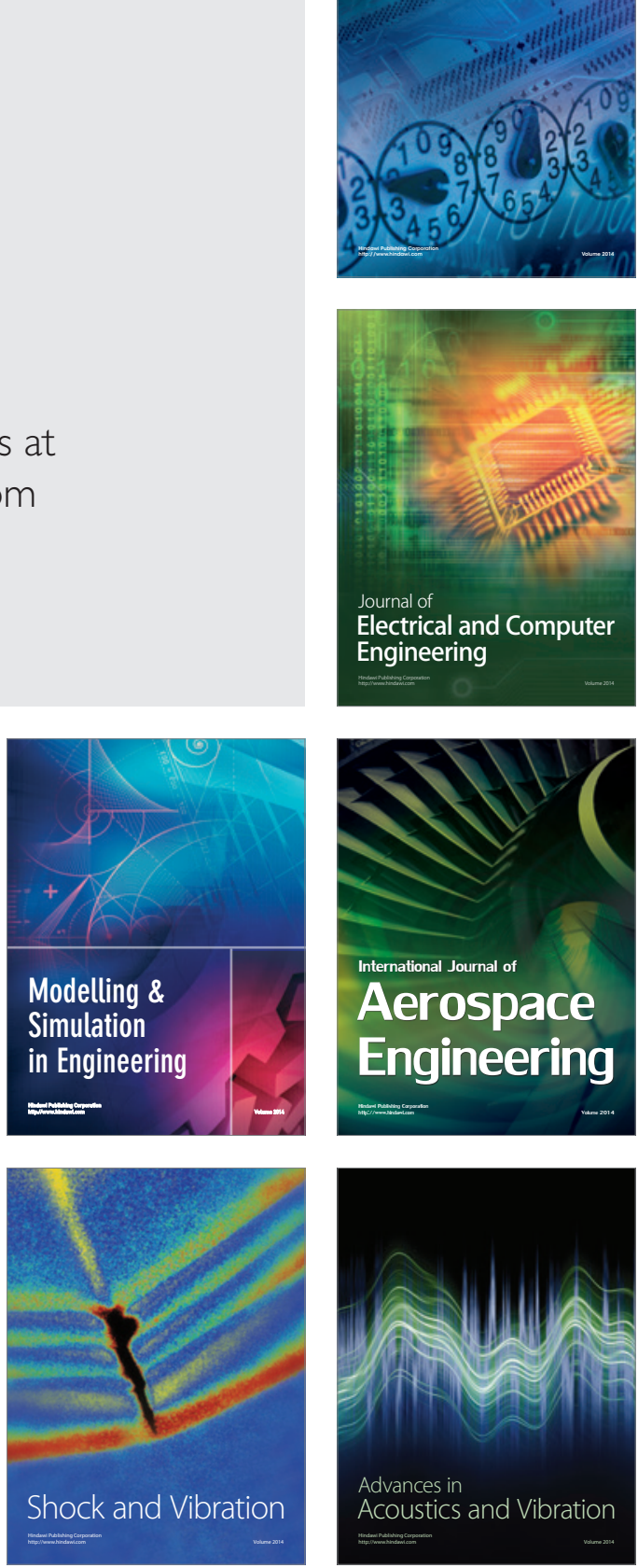